\title{
Kiñe dungu pian tañi lladkülen / Explico algunas cosas
}

Héctor Mariano ${ }^{1}$

Iñche ñi küdawfengen ka kom inchiñ taiñ küdawfengen kutrankawiñ ñi feychi weda dungu ñi rupan chi pu mineru welu ayelafiñ tañi fentre dungudungumeken chi pu longkolelu tüfachi país mew. Fillantü tripatripangey chi wingka notisia mew ñi felen engün. Tañi pu peñi doy pura mari antü entrin kutrankawün ñi meken engün tañi ingkayael kisu tañi mapu engün feychi wecheke che kimlu am engün ñi weneñmangen tañi mapu tañi fütake laku yem. Niewenolu am mapuche chew ñi küdawam engün chew ñi entukemum iyael feymew ta kewakewangey tañi mapu mew engün welu chi estado langumlangumyengepuy engün kisu ñi mapu mew, ilotumekengepuy engün kulliñ reke ñi ingkayael ñi kisu ñi mapu mew. Yamlay rume chi estado ñi kewakewangepun chi weñen mapu.

A mí, como trabajador, y a nosotros como trabajadores, nos dolió lo que sucedió con los mineros, pero no me gustó la actitud aprovechadora que tuvieron los gobernantes de este país, que mucho hablaron del tema. Todos los días, salía y salía en las noticas wingka lo que ellos estaban pasando. Mis peñi estuvieron más de 80 días en huelga de hambre para defender su propia tierra, por saber que la tierra les había sido robada a sus finados abuelos. Como los mapuches ya no tenían tierra donde sacar su cosecha, su alimento, entonces ha sido muy disputada la tierra, pero el estado los mata y los mata en su propia tierra, los carnea como animales por defender su propia tierra. No respeta el estado siquiera al ir allá a pelear una tierra robada. 